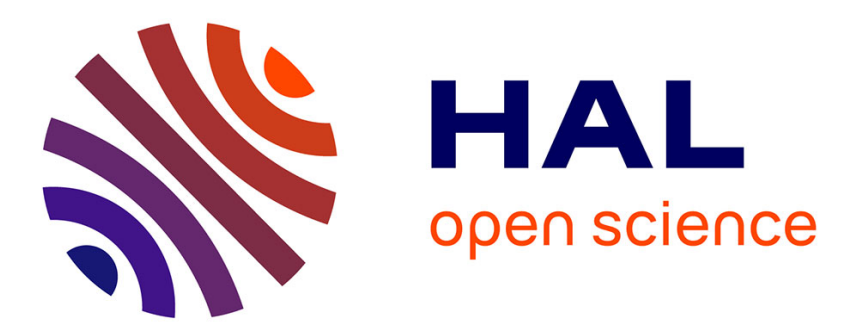

\title{
Potentiality of the photothermal surface displacement technique for precisely performed absorption measurement of optical coatings
}

\author{
P. Zimmermann, D. Ristau, E. Welsch, G. Langer, M. Reichling
}

\section{- To cite this version:}

P. Zimmermann, D. Ristau, E. Welsch, G. Langer, M. Reichling. Potentiality of the photothermal surface displacement technique for precisely performed absorption measurement of optical coatings. Journal de Physique IV Proceedings, 1994, 04 (C7), pp.C7-623-C7-626. 10.1051/jp4:19947147 . jpa00253205

\section{HAL Id: jpa-00253205 https://hal.science/jpa-00253205}

Submitted on 1 Jan 1994

HAL is a multi-disciplinary open access archive for the deposit and dissemination of scientific research documents, whether they are published or not. The documents may come from teaching and research institutions in France or abroad, or from public or private research centers.
L'archive ouverte pluridisciplinaire HAL, est destinée au dépôt et à la diffusion de documents scientifiques de niveau recherche, publiés ou non, émanant des établissements d'enseignement et de recherche français ou étrangers, des laboratoires publics ou privés. 


\title{
Potentiality of the photothermal surface displacement technique for precisely performed absorption measurement of optical coatings
}

\author{
P. Zimmermann, D. Ristau*, E. Welsch**, G. Langer*** and M. Reichling*** \\ LAYERTEC, Optische Beschichtungen GmbH, Blankenhainer Str. 169, 99441 Mellingen, Germany \\ * Universität Hannover, Institut für Quantenoptik, Welfengarten 1, 30167 Hannover, Germany \\ ** F. Schiller Universität Jena, Institut für Optik und Quantenelektronik, Max-Wien-Platz 1, \\ 07443 Jena, Germany \\ *** Freie Universität Berlin, Fachbereich Physik, Arnimallee 14, 14195 Berlin, Germany
}

\begin{abstract}
The absolute and comparative determination of the absorption of optical films by the photothermal-surfaceDisplacement-Technique (PTD) is only possible if the sample configuration is in agreement with the limits of the theoretical model. Carrying out simultaneous absorption measurements in the IR-region at $\lambda=10,6 \mu \mathrm{m}$ by using lasercalorimetry as well as the surface displacement technique, it can be demonstrated that the thermophysical properties of the film contribute to the probed surface displacement. The results of PTD measurements at a wavelength of $488 \mathrm{~nm}$ show, that there is a similar influence of the film properties on the PTD signal.
\end{abstract}

\section{INTRODUCTION}

Comparative measurements of the optical absorption of different film materials on the same substrates by PTD are only possible, if the following conditions of the theoretical PTD signal calculation $/ 1,2,3 /$ are fulfilled:

1. The film materials under investigation are thermally thin, i.e. the energy which is absorbed in the film results only in a deformation of the substrate; the deformation of the film itself may be neglected.

2. The propagation of heat from the film into the substrate is not influenced by the film properties and the interface between film and substrate.

In the most cases the experimental setup is characterized by low modulation frequencies and a film absorption coefficient being large compared to that of the bulk. Hence, the thermal waves, ge- 
nerated at the sample surface, are penetrating the substrate up to a thickness $\mu_{t h}{ } d_{f i l m}\left[\mu_{t h}{ }^{-}\right.$thermal diffusion length, $d_{\text {film }}$ film thickness]. It can be shown /l/ that the coupled heat diffusion equation as well as the thermoelastic equation may be adequately solved for the backing only, i.e. both the change in temperature and deformation of the thin film layer itself may be neglected: Only the backing temperature, caused by thin-film as well as substrate absorption, acts as the source term in an elastic equation for the backing deformation. Therefore, it has been suggested that the film be considered solely as heating source at the backing surface.

\section{EXPERIMENTAL}

These theoretical assumptions have to be checked before using PTD measurements to calculate the optical losses and, hence, to optimize the production process of optical coatings.

For this purpose, the optical absorption of several types of optical coatings for the laserwavelength $\lambda=10,6 \mu \mathrm{m}$ was determined by an adiabatic laser-calorimeter $/ 4 /$ and compared to the values measured by PTD $/ 3,5 /$.

To prove the reliability of the model's assumptions by experiment a diamond turned copper substrate was chosen, which approximately satisfies the conditions of the theoretical treatment. For the PTD-measurement in a vacuum-chamber at a pressure $p<1$ mbar the experimental results agree with the expected data according to the model calculation.

The capability of the PTD-method for absorption measurements on metallic coatings deposited on silicon has been tested with respect to the influence on the thin film thermal capacity and the heat transition from the film into the substrate. To do this, five samples, fabricated from one piece of Si substrate, are coated with Molybdenum-films of different thicknesses. The samples are measured in the PTD vacuum chamber ( $p<1$ mbar) and then in an adiabatic laser calorimeter [LCA] ensuring an absolute calibration which is independent of any coating thickness, thermal and thermoelastic properties. The result is given in Figure 1 , presenting the ratio of the PTD to the calorimetric response.

The appreciable variation with the thickness of Molybdenum coating can be explained by the thickness-dependence of the heat capacity of the film, the thermal reflection given by the ratio of the re- 
lated effusivities of the film and substrate material and of a possible thermal barrizr existing between metal film and the substrate. Assuming this, an effectively acting thermal reflection, increased by the thermal impedance at the related interface, leads to an enhanced heat reflection back to the metal overcoat. Hence, the ratio of PTD to LCA response will be decreased more strongly with respect to increasing film-thickness as it would be without any thermal impedance.

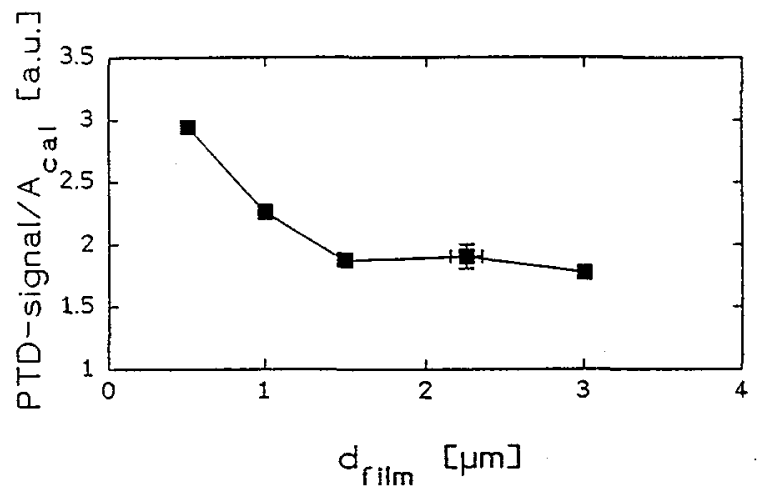

Fig. 1 :
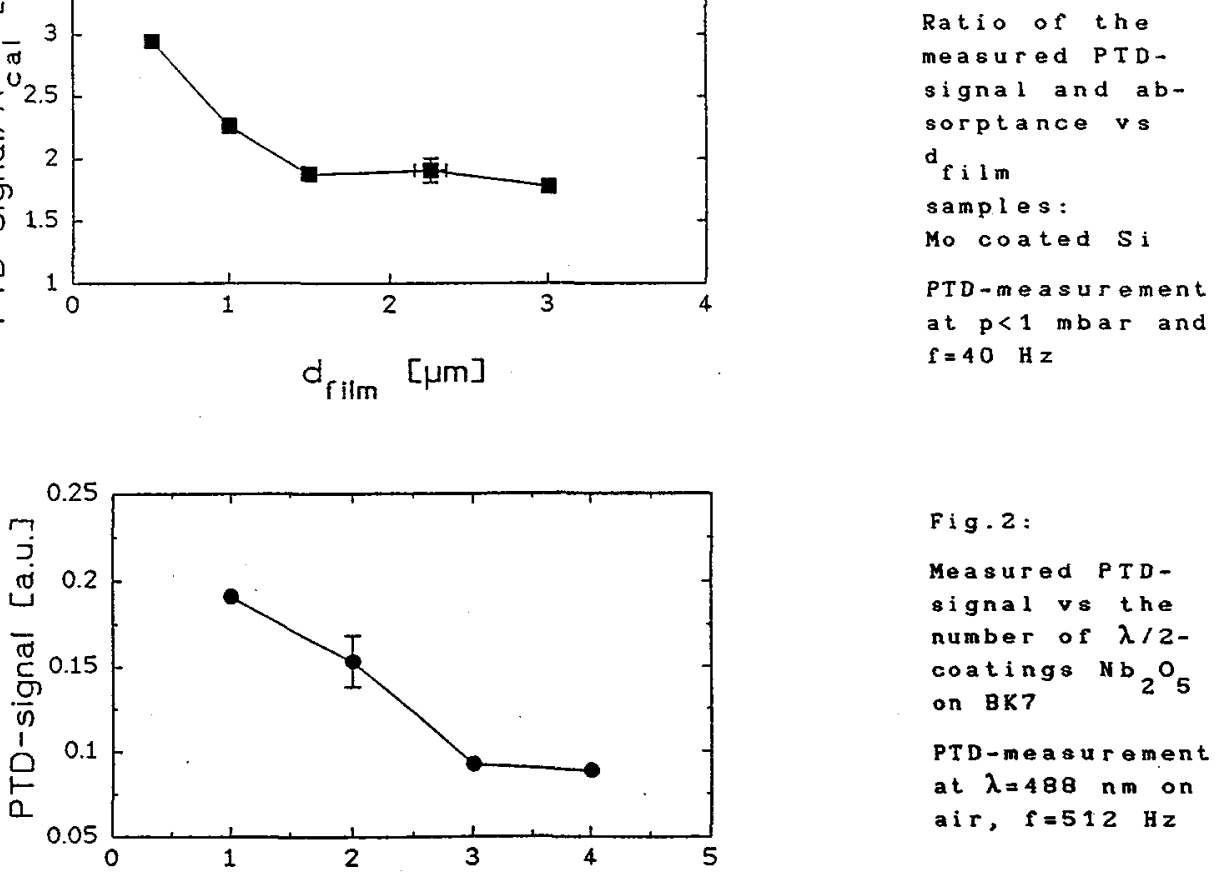

Fig. 2:

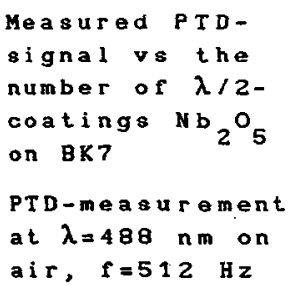

number of $\lambda / 2-\mathrm{Nb}_{2} \mathrm{O}_{5}$-coatings

The application of the PTD-technique to a multilayer system which has high reflectivity in the IR range shows similar results $/ 3 /$. In order to check, wheather the results obtained for IR-coatings are also valid for optical layer systems in the visible range, similar experiments were carried out at a laserwavelength of $488 \mathrm{~nm}$ $16 / .4$ BK7-substrates of identical thickness $\left(\Delta \mathrm{d}_{\mathrm{Bulk}} 1 \mathrm{\mu m}\right)$ were coated with $\mathrm{n} * \lambda / 2 \mathrm{Nb}_{2} \mathrm{O}_{5}(\mathrm{n}=1,2,3,4)$ on one side and with an antireflection coating for $488 \mathrm{~nm}$ on the other side. The optical ab- 
sorption increases linearly with increasing $n$, which should - according to the PTD model - also result in a linear increase of the PTD signal. However, the PTD measurements at a chopper frequency of $512 \mathrm{~Hz}\left(\mu_{\mathrm{th}} \approx 25 \mathrm{~mm} \gg \mathrm{d}_{\mathrm{film}}<500 \mathrm{~nm}\right)$ show, that the PTD signal decreases with increasing number of $\lambda / 2$-layers. Thus, the behaviour of $\mathrm{Nb}_{2} \mathrm{O}_{5}$ layers on BK7 during PTD measurements is similar to that of Mo layers on si which was discussed above. This means, that the properties of the layer and of the interface modify the PTD signal also in the case of single dielectrial layers which are transparent in the VIS.

\section{CONCLUDING REMARKS}

By performing simultanous absorption measurements at $\lambda=10,6 \mu \mathrm{m}$ on thin films using lasercalorimetry and photodisplacement techniques, a significant dependence of the PTD signal on the film thickness was detected. This may be caused by the increased thermal ratio of effusivity i.e. the considerable thermal reflection at the film substrate interface, which is thought to be further amplified by a thermal impedance at the related interface.

The results at the laser wavelength $\lambda=10,6 \mathrm{\mu m}$ as well as in the VIS-region at $\lambda=488 \mathrm{~nm}$ indicate that both thermal influence of the overlayer and possibly the existing non-ideal thermal contact between film and substrate must be taken into consideration. Moreover, the influence of different thermoelastic properties of the film and the substrate material have to be considered also. Thus, no general calibration can be achieved: For each sample configuration and material, dependent on deposition technology, the calibration has to be checked in order to ensure reproducible measurements.

\section{ACKNOWLEDGEMENTS}

The authors are indebted to J.Ebert (Laseroptik GmbH Germany) for sponsoring the absorption measurements.

\section{REFERENCES}

/1/ E. We1sch: J.Mod.Optics, Vol.38, 1991, 2159

/2/ E. Welsch, M. Reichling: J.Mod.Optics, Vol.40(8), 1993, 1455

/3/ P. Zimmermann, D.Ristau, E.Welsch: Appl.Phys.A, 1994

/4/ P.zimmermann: Exp.Technik der Physik, Vo1. 38, 1991, 213

/5/ P.Zimmermann: Ph.D.thesis, FSU Jena, 1994

/6/ M.Reichling: Ph.D. thesis, FU Berlin, 1991 